\title{
Jovita Feitosa, polissêmica mulher
}

Gislania de Freitas Silva

Resenha: CARVALHO, J. M. de. Jovita Alves Feitosa: Voluntária da pátria, voluntária da morte. São Paulo: Chão Editora, 2019.
O que me espanta é a força
De um feminil coração.
É ver num peito de corça
Brio, valor de leão!
E sob a forma delgada
De uma mulher delicada
Ver um'alma alimentada
Do fogo de uma explosão!
(Franklin Távora)

Conhecida dos cearenses por emprestar seu nome a uma importante avenida da capital, nos últimos anos, Jovita Feitosa teve sua memória resgatada como exemplo de mulher forte, guerreira e destemida pelos movimentos de mulheres na luta por justiça e igualdade social. Seu nome voltou a ter notoriedade em âmbito nacional e isso se deve também à recente promulgação da Lei $\mathrm{n}^{\circ} 13.423,{ }^{1}$ em 2018, que inscreve a jovem no Livro dos Heróis da Pátria. $^{2}$

1 O projeto de Lei $\mathrm{n}^{\circ} 3.683$, de 2012, foi proposto pela deputada Sandra Rosado, do PSB do Rio Grande do Norte, tornando-se lei somente em 2018.

2 A primeira mulher a ter seu nome inscrito no livro foi a enfermeira baiana Ana Neri.

\section{$\overline{\text { Gislania de Freitas Silva }}$}

Doutoranda do Programa de Pós-Graduação em Sociologia da Universidade Federal do Ceará (PPGS - UFC), mestre em Sociologia pelo PPGS - UFC, licenciada em Ciências Sociais pela Universidade Estadual do Ceará (UECE) e professora de Sociologia na rede estadual de ensino do estado do Ceará (SEDUC-CE) desde 2010. E-mail: gislanialyra@gmail.com 
Com seu indiscutível talento historiográfico, José Murilo de Carvalho nos brinda com uma obra em que narra com delicadeza a trajetória de coragem e ousadia e o desafortunado fim da jovem cearense, buscando separar o "mito" da realidade. Além do refinamento analítico, a obra traz imagens de jornais de época e fotografias. Singular também são as fontes utilizadas pelo autor. Além dos artigos jornalísticos coetâneos, Carvalho (2019) vale-se fartamente de poemas escritos, exaltando a Guerra do Paraguai e o patriotismo, mas, principalmente, poemas escritos em louvor à corajosa amazona. Em suas palavras, "textos patrióticos em geral não primam pela qualidade literária, mas refletem bem o ambiente e as emoções do momento" (CARVALHO, 2019, p. 50).

O livro se inicia com a transcrição de uma pequena biografia publicada em 1865, por José Alves Visconti Coaraci, que usou o pseudônimo Um Fluminense. Esse relato de época é o mais completo da vida da Jovita e a fonte mais confiável de informações sobre sua trajetória. Ademais, traz uma das poucas fotografias da jovem de que temos registro. Diante do material fragmentado, disperso em jornais e revistas, Carvalho (2019) divide sua narrativa em quatro tópicos: seu alistamento ao corpo de voluntários; os "37 dias de glória", em que a jovem recebe diversas homenagens por onde passa em seu percurso até a capital; sua rejeição para compor as fileiras do exército; e, por último, seu trágico fim aos 19 anos.

Filha de sertanejos da região dos Inhamuns, pobre e semianalfabeta, aos 16 anos, Jovita vai residir com um tio na cidade de Jaicós, no interior do Piauí. Lá, ouve os rumores sobre a terrível guerra que se trava ao sul do país com o vizinho Paraguai. Decide, então, se alistar ao Corpo de Voluntários da Pátria e parte com um grupo de jovens com o mesmo intento, rumo à cidade de Teresina. Ao ser descoberta e interrogada acerca dos motivos que a levaram a se travestir em roupas socialmente consideradas masculinas e a se alistar aos voluntários, a jovem declara sua ojeriza aos paraguaios e menciona as violências impetradas contra as mulheres mato-grossenses pelo exército inimigo. Tal sentimento a invadiu a ponto de não ter saída senão pegar em armas. Somente quando soube da proibição imposta às mulheres resolveu modificar sua aparência para poder servir ao país com armas em punho. 
Às mulheres, cabia o papel de limpar as fardas, cozinhar, cuidar dos soldados e prestar cuidados médicos no posto de enfermeira. Jovita foi categórica: se for para executar trabalhos femininos, os faria em casa. "Fosse por amor da pátria, por amor de homem, ou por solidariedade feminina, sua decisão foi própria de alguém capaz de grandes paixões e de decisões difíceis" (CARVALHO, 2019, p. 63).

Em seu trajeto de Teresina à Corte, Jovita foi recebida com festejos pela população local e pelos poderosos, que a felicitavam por sua bravura e por ser um exemplo de patriotismo. Sua fama correu o Brasil, tornou-se símbolo da luta brasileira contra o inimigo paraguaio, a "Joana D'Arc brasileira". Carvalho (2019) indica que o governo se valeu da ousadia da jovem para dar substância à sua propaganda, conclamando voluntários para a guerra. Foram "37 dias de glória", assinala o autor. Contudo, a chegada ao Rio de Janeiro soçobrou a aventura da amazona. Foi-lhe negado o direito de ir batalhar e seu título de segundo-sargento foi-lhe retirado.

Em meio à tanta ovação e interesse, houve aqueles para quem a aventura de Jovita era uma afronta à moral e deveria, como de fato o foi, impedida. Incomodava sua recusa aos papéis previamente estabelecidos para as mulheres, sua ousadia em invadir um espaço público eminentemente masculino quando lhe cabia resguarda-se ao âmbito privado, restrito, da vida doméstica. O Jornal do Commercio trouxe um texto - escrito por alguém que se identificou apenas com as iniciais J.M.C - que ilustra bem esse traço sexista da época:

Nos exércitos em campanha, muitas mulheres, quer de soldados ou não, acompanham e prestam, reunidas a eles, serviços úteis como sejam lavar, cozinhar e engomar a roupa das praças. A mulher poderá servir quando muito para oferecer um ou outro cartucho, um ou outro cantil d'água em ocasião de fogo, ao soldado que peleja; mas não poderá jamais lançar mão de um sabre e bater-se quando se apresentam as ocasiões. (...) Foi um oferecimento justo, honesto, nobre, e muito patriótico, mas cumpre para a honra e moralidade do país, que ele não seja imitado (CARVALHO, 2019, p. 96 - 97). 
Como explicitado no trecho supracitado, a jovem cearense rompeu com as expectativas direcionadas às mulheres de sua sociedade. Em outras passagens selecionadas por Carvalho (2019), fica implícito também a ligação entre racismo e sexismo, subjugando mulheres, brancas e negras, e homens negros escravizados. A introdução jocosa ao poema Jovita, escrita por O Roceiro da Capital, traz a seguinte recomendação: "Diga à Comadre Cecília, que cuidado com suas negras; podem todas elas querer vir pegar na reúna. Por isso, ela que leia esta versaria que já fizeram no Rio de Janeiro contra as tais Jovitas" (CARVALHO, 2019, p. 93). Primeiro, as mulheres se rebelam, depois os escravizados. O poema traz uma série de estrofes em que o Roceiro faz troça com a ousadia da jovem, como no trecho a seguir: "E senão vejam com calma/ Se não causa hilaridade/ Um sargento brasileiro/ Feito irmã de caridade (CARVALHO, 2019, p. 94).

Passada a empolgação inicial e diante da recusa de servir ao exército, Jovita decide voltar para casa. Lá chegando, não encontra acolhida e acaba por retornar à capital. Sozinha, sem apoio nem orientação, junta-se às "elegantes do mundo equívoco". Acaba por viver um romance com o engenheiro galês William Noot que, findo seu contrato para a companhia de esgotos, retorna ao seu país, deixando para trás a jovem, sem nada além de uma carta escrita em inglês. Desiludida diante de tantas desditas, Jovita dá cabo da própria vida no quarto onde residia seu amante. Diversos jornais escreveram o obituário, narrando a desventura da jovem patriota e, graças à intervenção de Francisco Mendes de Araújo, "veterano da guerra de independência da Bahia", trabalhador da Santa Casa (administradora do cemitério), que "coletou doações", Jovita foi sepultada em um túmulo digno, não em uma vala comum. Seu final trágico também foi expresso em versos, estes publicados na Semana Illustrada: "A pátria e os seus amores/ De Jovita era o pensar/ A pátria ofendida/ Jovita busca vingar [...]/ Se a pátria não quer seu sangue/ Nem amor quer suas flores/ Aceita a morte branda/ O termo das suas dores" (CARVALHO, 2019, p.116 - 117).

Carvalho (2010) sublinha que, mesmo no período pós-independentista, a ideia de pátria não era bem definida e os sentimentos e afetos eram circunscritos às províncias, como atestam os 
movimentos separatistas do período regencial. Segundo o autor, a Guerra do Paraguai teve grande importância na construção de uma identidade nacional. É nesse contexto que a imprensa passa a trabalhar na "produção" de heróis militares pátrios. O tratamento dado a Jovita Feitosa é icônico nesse sentido. Destaca o autor que:

O início de um sentimento de pátria é também atestado pela poesia e pela canção popular sobre a guerra. Algumas poesias e canções sobreviveram até hoje na memória popular. Muitas falam do amor à pátria e da necessidade de a defender, se necessário, com o sacrifício da própria vida (CARVALHO, 2010, p. 79).

Consagrou-se, no tratamento analítico dedicado a Guerra do Paraguai, a ideia da coerção, que acabou por eclipsar o ímpeto patriótico de voluntários e intelectuais de várias regiões do Brasil, nos primeiros meses da guerra. A longa duração do conflito foi, aos poucos, minando os ânimos (CARVALHO, 2010; 2019).

Para concluir, Carvalho (2019) destaca que a trajetória de Jovita a tornou polissêmica, carregando diversos adjetivos que a levaram de mártir patriótica a la Joana D'Arc à cortesã Théroigne de Méricourt. Após sua morte, tornou-se uma "heroína trágica", rejeitada por todos os seus amores: a pátria, o pai e o amante. Nas palavras do autor:

Serviu à exaltação romântica da mulher como heroína e símbolo da pátria, entidade pública por excelência. Mas, ao tentar sair do mundo simbólico, ao insistir em lutar como guerreiro, atividade masculina por excelência, feria os valores de uma sociedade dominada por práticas patriarcais. Esses valores eram também atingidos pela transformação de Jovita em mulher pública no sentido moral do termo, isto é, inimiga da privacidade do lar. Não foi pequeno mérito da voluntária ter sido pioneira na luta pelo papel público das mulheres, por sua libertação da prisão doméstica, pagando por isso alto preço (CARVALHO, 2019, p. 123).

Apesar de ser um livro curto, com 151 páginas, é rico em documentos. Traço de sua vasta obra, José Murilo de Carvalho não faz conjecturas nem afirmações que não possam ser comprovadas. 
A utilização de poemas pode ser considerado uma fonte histórica inusual, mas isso não diminuiu o rigor analítico de Carvalho (2019) e, ao longo da leitura, percebemos seu cuidado para não incorrer em uma escrita romanceada e fictícia da vida de Jovita. Exaltou, sim, a bravura inequívoca da jovem e não se deixou levar pelo idílio patriótico que sacraliza figuras públicas. Exatamente por ser humana, as qualidades de Jovita merecem ser contadas e recontadas. Uma heroína cuja ousadia é digna do epíteto.

\section{REFERÊNCIAS}

CARVALHO, J. M. de. Cidadania no Brasil: o longo caminho.13. ed. Rio de Janeiro: Civilização Brasileira, 2010. 